SHS Web of Conferences 24, 02011 (2016)

DOI: $10.1051 /$ shsconf/20162402011

(C) Owned by the authors, published by EDP Sciences, 2016

\title{
Innovation and exploration of college students' moral education carrier in the transformation period
}

\author{
Xiaofang $\mathrm{Yi}^{1,2}$ \\ ${ }^{1}$ Department of Scientific Research and Development, Wuhan Vocational College of Software and Engineering, \\ Wuhan, Hubei, China \\ ${ }^{2}$ School of Economics and Management, Huazhong Agricultural University, Wuhan, Hubei, China
}

\begin{abstract}
Due to the specificity of college students, the comprehensive traditional moral education mode based on the tutorial system which is assisted with the counselor system and complemented by college student's self-learning is unable to meet the education demand of college students at present. This paper proposes a new kind of work carrier - assistant tutor system through analyzing the current status of moral education carrier of the college students. The result shows that, giving full play to the assistant tutor system is conducive to helping strengthen the relation between tutors and college students, perfect the moral education mode of college students, and improve the moral education level and quality of college students.
\end{abstract}

Keywords: transformation period; assistant tutor; moral education; carrier innovation

\section{INTRODUCTION}

Moral education is a basic requirement of personal quality training in the civilized society, and also a special target to adapt to the transformation of social system, and meet the talent training in the aspect of ideological quality ${ }^{[1]}$. With the continuous progress of the society, the state pays more and more attention to education, and the moral education of college students is also improved and innovated constantly. In the new era, the exploration target about the moral education of college students is not only organic integration with "academy" and "life", but also exploration of the innovative mechanism of postgraduate management ${ }^{[2]}$. The college students are the most active young groups in the society with a strong contemporaneity, so the moral education shall also be relatively changed. This paper proposes to create the assistant tutor system of college students in the context of tutorial system, and makes efforts to innovate the moral education carrier in order to solve the existing shortcomings in the process of the current educational management of college students, and improve the mechanism and carrier of the educational management of college students.

\section{QUESTION POSING: DIALECTICAL CONSIDERATION OF MORAL EDUCATION CARRIER OF COLLEGE STUDENTS}

Moral education is an important part in the overall education of college students. As a special kind of social practice activity which is different from face-to-face teaching, it generates along with the emergence of college students, which not only serves for the management of college students, but also has the constraints of the current training mode, and also confronts with the impact of the education system reform. Such an impact not only embodies the conflict between the unitary value orientation of the education and pluralistic values in society, but also reflects that the moral education mode at the present stage is unable to meet the actual contradiction required in the current education management of college students ${ }^{[3]}$.

\subsection{Weakened tutor management in moral education of college students}

Based on "I and Thou" theory of Buber Martin and under the new "double-subject" relations between students and teachers, how to overcome this kind of "system alienation" is particularly important. [4] Therefore, there is a must to attach importance to the 


\section{SHS Web of Conferences}

direct dialogue between teachers and students, keep sincere exchange between teachers and students, and prompt them not to be confined with the system. The tutor shall not only guide and cultivate the students' scientific research capacity, and promote the college students to complete their studies well, but also always pay attention to the ideological trend of students. Tutors attach more importance to academy and less importance to education, because various objective or subjective difficulties in implementing the system and the derail of tutor system which is originally established and individually instruct undergraduates' study, scientific research, morality, daily life and responsible for their teaching. Due to the impact of utilitarianism, the mentoring relationship originally maintained with emotion is evolved into the "boss system"-oriented relationship by the research results, the exchange between tutors and students reduces increasingly, and the exchange content also has certain limitations. Taking the survey of the frequency of interaction between tutors and college students which is recently conducted by an A University as an example, the result shows that most of content of exchange between tutors and college students are project experiments and project papers, accounting for $32.9 \%$; the discussion of individual's recent living conditions and ideological changes is very little; the moral education dominated by daily penetration and systematic guidance basically fades out of the range of conversation between tutors and college students. The model of separating the professional learning from daily management is not ideal for moral education of college students.

\subsection{Lagging training of self-management skills of college students}

According to Drucker's management theory, individuals should manage themselves, enhance advantages and avoid disadvantages according to their own values and adept fields. Therefore, in the moral education of college students, there is a need to carry out a number of suitable cultural and sports activities by the use of their broader field of knowledge and better self-cognitive competence, and organize a number of high-level academic forums, seminars, lectures and other activities to guide and attract the students' scientific research enthusiasm, give full play to the students' subjective initiative, and improve the students' overall quality through unconscious influence, and carry out timely moral education to promote the students' comprehensive development. However, in the long run, the moral education mode of following one's own inclination or blindly running throughout the students will inevitably lead to the lack of moral education of college students. On the whole, China's college students are restricted by the specialization of work, the social background and the age level and values, and their group structure has certain decentrality and complexity, so there is a lack of suitable platform to shape their group cohesion. Their own good management ability is not exerted well, and attention is only limited to their academic attainments and how to get appreciation of tutors. Good implementation of moral education is furthered by effectively mastering the practical background under the group rendering. Therefore, self-management ability of the college students is lack of effective training to create corresponding correlation with the moral education.

\subsection{Single tutor guidance pattern with the support of the party and the league organizations}

The traditional moral education of college students is a single top-down and consistently vertical management mode, so those administrative staffs of college who are tired to cope with superior and subordinate work are lack of motivation to educate college students from the perspective of ideological and political theory education. What's worse, it's more difficult to have spirit and thought to consider how to enhance the initiative and effectiveness of the management. The moral education mode which is generally with the carrier of dormitory, class, the party, the league and the school organizations is not suitable for college student groups with dispersed residence and weak class concept. Therefore, we cannot solely rely on the counselors and political workers to understand the college student's thought, learning and living conditions through some simple and formal methods, because we will usually overlook the pressure and psychological problems caused by learning, life, employment and other aspects through this method. What's worse, for some emergencies or mental illnesses that are difficult to detect, the counselors could not timely carry out counseling and judge as well. Therefore, insufficient moral education of college students becomes more and more obvious under the new situation.

\section{CAUSE ANALYSIS: MECHANISM CONSIDERATION OF WEAKENING MORAL EDUCATION CARRIER OF COLLEGE STUDENTS}

China's traditional moral education of college students has the following three major problems: the monologue-type tutor teaching, the utilitarian self- management and the guidance of the alienation-type counselor. The failure in the education and management strategies not only makes the effectiveness of college's moral education be sharply weakened and not matched the expected result, but also aggravates the embarrassment of the teachers and students ${ }^{[5]}$. In order to meet the current need of moral education in colleges, give play to the group counseling effects, and achieve "win-win" moral education effect ${ }^{[6]}$, we urgently need to excavate incentives of failure in the 
working mechanism of traditional moral education, and facilitate leak detection and vacancy filling through innovation of the moral education carrier.

\subsection{Moral decline of the traditional moral education carrier under the failure of organization and coordination}

The modern organization confronts with a complex environment, which is prone to be in a state of chaos. Therefore, the cooperation theory believes that, the coordination between internal elements of the subsystem can produce a win-win effect, namely, $1+1>2$. On the contrary, it is prone to cause the failure and even collapse of the working mechanism. The enrollment expansion causes an increasingly huge number of China's college students, and the number of college students is discordant with the proportion of tutors and counselors. In addition, the traditional moral education carrier is from the migration of the undergraduate dormitory, class and all levels of the party, the league and the school organization, as well as college student's counselors and administrative staff from all levels, and ignores main distinctive features and conflicts in the moral education of college students: In particular, the internal mental function of college students is imperfect, and the academic and employment pressure is huge. The scientific research tasks of the tutors are arduous, and conversational teaching mode is not yet in full swing. The working mechanism of counselors is imperfect, and there is a problem in the relationship between helping and educating. The above problems reflect the failure of coordination in the ideological and political education, and the subject fails to form a cohesive force, resulting in the failure of current moral education carrier of college students.

\subsection{Moral decline of the traditional moral education} carrier under the absence of management system

The management system is a generic term of a variety of policies, rules, procedures, behavior patterns and other systems that are formed in the process of organization and management. Relying on the legitimate and rational management system, the organizations can enhance their own management transparency, accuracy, efficiency, stability and so on. Currently, China's colleges have introduced various types of characteristic college student management system, and most of them are still subject to the trial implementation of tutor's responsibility system. However, compared with the relatively mature tutorial system in University of Oxford, University of Cambridge or other foreign countries, China's system has many shortcomings: the lack of system supply, and new problems that are not completely solved; the system operation which is often too arbitrary loses the authority of management system; the supply of system content is not required and lack of human care; the sys- tems have prominent contradiction without supporting and smooth convergence between systems. These problems make the originally rigid management system be prone to have defects, resulting in the failure of working mechanism to follow the management system.

\subsection{Moral decline of the traditional moral education carrier under the weakening of management subjects}

In colleges, there are contradictions and conflicts between the teaching subject represented by the counselor and the taught subject represented by the college students in the psychology, role, cognition and other levels, so they are unable to adapt to changes of educational development in the new era, and the effective implementation of moral education is also affected. Obviously, due to the specificity of college student group, the comprehensive traditional moral education mode based on the tutorial system which is assisted with the counselor system and complemented by college student's self-learning is unable to meet the education demand of college students at the present, and it is constantly weakened in carrying out specific work. However, the assistant tutors generated from the scientific research teams can solve this problem. This is because the college students mainly do scientific research in the laboratory at the learning stage. With respect to the dormitory and class, the relations between the research team members are closer. The assistant tutors can assist the tutors in carrying out a number of academic lectures, and improving and cultivating the scientific research interests and academic abilities of college students. In addition, the assistant tutors also assist the counselors in focusing on the college students' learning, life and state of mind at any time, and implementing the related work arrangement of the school and faculty, and organizing various cultural and sports activities. The assistant tutor system can be better to relieve various problems in the moral education of college students at the present stage, and adapt to the development of China's higher education in a new round of system reform, which has a very important significance in enhancing the effectiveness of moral education toward college students.

\section{COUNTERMEASURES PROSPECT: INNOVATION EXPLORATION OF MORAL EDUCAITON CARRIER OF COLLEGE STUDENTS}

The moral education of college students is a system integrated with the students education, academic practice and construction of the party, the league and the school, which not only has a close relation with the educational level of colleges, cultural atmosphere and campus environment, but also has internal coordina- 
tion mechanism with the degree of adaptation of the student management system. Just as the viewpoint of "relationship ontology" advocated by Buber Martin, the establishment of relation between "I and Thou" is a key to build harmonious and equal teacher-student relationship ${ }^{[7]}$. We carry out the relevant questionnaire survey for 166 college students and 154 college student's tutors in an A University, and explore and implement the college student management mode characterized by the "assistant tutor", so as to improve the teacher-student relationship, enhance the college student management level and efficiency, and achieve innovation of ideological and political education of college students under the existing framework of tutorial system in the colleges.

\subsection{Connotative definition of assistant tutors}

The questionnaire survey shows that, two groups have more obvious differences in the cognition of the assistant tutor post. The student groups are more inclined to view the assistant tutor as a role of self-serving for college student groups. The tutor groups agree that the job function of assistant tutor is to assist the tutor in the management of daily affairs. From this point, we can see that different tendencies of cognizing the assistant tutors caused by the difference in the starting point indicate that both of them have obvious conflict between thoughts and exchanges, which also affirm the significance of the post setting, that is, the establishment harmonious student-teacher relations based on the genuine relation between "I and Thou". In fact, the paper believes that, speaking from the role definition, the "assistant tutor" refers to the student individual who is identified from the student groups managed by the tutor and responsible for assisting the tutor in managing and guiding other college students in the experimental group; from the perspective of the nature of function, the "assistant tutor" is a novel student management mode created and implemented based on the features of college students. In terms of the job content, the assistant tutor oriented by senior students shall act as a communication bridge between tutors and students, so as to build a smooth, effective and intimate communication environment for both parties, and improve the alienation of teacher-student relationship due to "system loss". In addition, the assistant tutor is involved in the tutor and student groups as a studentship, so he/she is easier to understand and grasp the mental activity and mental state of the college student group, who can not only assist the tutor in assuming the responsibility of helping students by students, but also self-inspect problems and shortcomings in the student groups as a third party, and then directly go into the heart through a confused and bemused contradictory presentation, and deeply excavate inner needs and desires, and guide the college student groups to learn self-awareness and self-responsibility, so as to escape from the dilemma lost in the group due to over-dependence on the system ${ }^{[8]}$.

\subsection{Development of the role of assistant tutor system}

The exploration and practice of the assistant tutor system in an A university further proves that the assistant tutor system helps strengthen the relations between tutors and students, and effectively compensate for the system shortcomings in the traditional moral education. The assistant tutor system will establish more favorable and harmonious relations of the direct dialogue between tutors and students. More specifically, the establishment of direct relations between "I and Thou" lays the foundation to break the barriers between people, and realize genuine dialogue between tutors and students. From the perspective of students, the assistant tutor will be a representative of the student group, and exchange the considerations and thoughts of students with tutors. Escaping from the role of "collective slavery", the students will really realize "personal responsibility of the life and world" ${ }^{[9]}$, and reach the status of equal exchange with the tutor, and give full play to the role of the student's subjectivity; from the perspective of tutors, as a third party, "Thou", the assistant tutor is not only the voice of the students, but also the "spokesman" of the tutor, which will be more conducive to the tutor to deliver true feelings to the students. Meanwhile, the establishment of such a more direct relationship will make the tutor listen to the student's voice clearly and understand the student's personality trait, so as not to blindly follow the relevant provisions of the tutorial system and stimulate the tutor autonomy. Buber Martin believes that, currently, people are lost in the self-developed system. The subjectivity of "I" tends to disappear, resulting in system alienation crisis. The setup and presence of the assistant tutor system is just the repair and improvement of "Subject-I".

\subsection{Scientific arrangement of the assistant tutor system}

The college students have a high educational level, prominent sense of democratic participation and strong self-management ability. In the process of cultivating the ideological and political quality, and growing up and becoming excellent, they should embody their own initiative, consciousness and participation. Nowadays, the assistant tutor system model is still at the exploration stage, including the development of a complete set of rules and regulations and implementation approaches, such as selection, management, incentive and so on. In the survey report, we find that nearly half of the assistant tutor is personally appointed by the tutor, and the tutor occupies a high initiative, which is prone to suppress the students to give play to their autonomy; in terms of the additional allowance for the assistant tutors, $74.1 \%$ of respond- 
ents indicate that, failure in receiving allowance granted in the name of tutor or college will virtually lead to deny the labor outcome of the students. Therefore, the premise of successful implementation of the assistant tutor system should focus on establishing scientific and perfect rules and regulations. Only the detailed scope of responsibility can help guide and instruct the students to recognize their own mission and responsibility; but more importantly, it is to focus on realizing the education automaticity, eradicating administerization and bureaucratization from teaching management, so the teachers and college students are no longer bound by any form, and release their positive energy which is inherent in their heart. Only in the free and autonomous space can people really shoulder their responsibilities.

\section{CONCLUSION}

Nowadays, China has entered a critical stage of the universalness and popularization of higher education. So what's the direction should China's higher education step forward, and how to improve the cultivation method of college Students? These are the current questions we must answer. Since the original triune moral education mode is unable to meet the needs of the management of college students, from the perspective of philosophy or realistic demand, the implementation of the assistant tutor system can be an effective way to explore to improve the training mode of college students, strengthen scientific research level and comprehensive ability of college students, enhance interaction between teachers and students, and establish a harmonious teacher-student relationship. In the direct dialogue between "I and Thou", and in a genuine and harmonious atmosphere, we understand ourselves due to recognizing ourselves and understand others due to understanding ourselves, so the tutors and students are difficult to fall into a dilemma of system loss and human alienation, and the teacher-student relationship will be more harmonious and friendly. We hope that, the assistant tutor settings will bring new ideas and opportunities for the moral education of China's college students in the new era.

\section{REFERENCES}

[1] Li Kangping. 1998. Strategic Conception of Improving the Ideological and Ethical Standards of the Chinese Nation - Brief View of Deng Xiaoping's Ideology of Moral Education. Educational Research, (10): 3-8.

[2] Zhang Fuliang. 2002. New exploration of postgraduate moral education. Ideological Education Research, (6): 34-35.

[3] Gao Baoquan. 2006. Dialectical and rational analysis of the effectiveness of moral education. Ideological education research, (2): 25-28.

[4] Chen Yufen. 2012. Analysis of postgraduate tutorial system--viewing angle based on the philosophy of Buber - Martin. Educational Research Monthly, (4): 29-31

[5] Joanne Wasykowski. Perspectives of Teacher Assistants Working with Students with Diverse Learning Needs [EB/OL].https://www.uleth.ca/dspace/bitstream/handle/1 0133/152/MQ68350.pdf?sequence=3.

[6] Li Fangqiang. 2005. Reflections of universities to explore and implement "little tutorial system of moral education". Ideological \& Theoretical Education Tribune, (10): 49-50.

[7] Buber Martin. 1958. I and Thou. New York: Charles Scribner's Sons

[8] Chen Yufen. 2012. Analysis of postgraduate tutorial system - viewing angle based on the philosophy of Buber Martin. Educational Research Monthly, (4): 29-31

[9] Buber Martin. 1965. Between Man and Man. New York: Macmillan Co.

10] Buber Martin. 1958. I and Thou. New York: Charles Scribner's Sons. 